\title{
Physicochemical and Sorptive Properties of a Phosphorylated Mercerized Cotton Fabric
}

\author{
Roman Solovov*(D), Anfisa Perevoznikova, Alexander Seliverstov, Alexey Shapagin (D, Alexandr Fedoseev, \\ Vitaly Milyutin (D) and Boris Ershov (D)
}

check for updates

Citation: Solovov, R.; Perevoznikova, A.; Seliverstov, A.; Shapagin, A.; Fedoseev, A.; Milyutin, V.; Ershov, B. Physicochemical and Sorptive Properties of a Phosphorylated Mercerized Cotton Fabric. Polymers 2021, 13, 3756. https://doi.org/ $10.3390 /$ polym 13213756

Academic Editor: Luis Alves

Received: 21 September 2021

Accepted: 25 October 2021

Published: 30 October 2021

Publisher's Note: MDPI stays neutral with regard to jurisdictional claims in published maps and institutional affiliations.

Copyright: (c) 2021 by the authors. Licensee MDPI, Basel, Switzerland. This article is an open access article distributed under the terms and conditions of the Creative Commons Attribution (CC BY) license (https:// creativecommons.org/licenses/by/ $4.0 /)$.
Frumkin Institute of Physical Chemistry and Electrochemistry of the Russian Academy of Sciences, 40 Obruchev Street, 117342 Moscow, Russia; perevoznikova1723@mail.ru (A.P.); alex_sel@bk.ru (A.S.); shapagin@mail.ru (A.S.); a.fedosseev@gmail.com (A.F.); vmilyutin@mail.ru (V.M.); ershov@ipc.rssi.ru (B.E.)

* Correspondence: roman_solovov@mail.ru

Abstract: A process of phosphorylation for a mercerized cotton kersey fabric was investigated. After wet oxidation, the phosphorus content in each sample was determined by spectrophotometric analysis. The range was 0.179 to $0.950 \mathrm{mmol} \mathrm{g}^{-1}$. A significant decrease in the tensile strength of samples resulted from an increase of phosphoric acid concentration in the phosphorylating solution. The mercerization has a positive impact on the process of phosphorylation, as the phosphorus content was found to be three times higher in the samples that underwent mercerization. The sorption properties of phosphorylated cotton fabric were studied using the $\mathrm{Cu}^{2+}$ sorption process as a reference. The value of the static exchange capacity for the phosphorylated fabric was determined to reach its maximum when the concentration of the $\mathrm{H}_{3} \mathrm{PO}_{4}$ in the phosphorylating solution was $1.40 \mathrm{M}$, and was found to be $1.48 \pm 0.11 \mathrm{mmol} \mathrm{g}^{-1}$ with the phosphorus content equal to $0.898 \pm 0.090 \mathrm{mmol} \mathrm{g}^{-1}$. The sorption of $\mathrm{Cu}^{2+}$ by a single phosphorus-containing group occurred for samples with phosphorus content not exceeding $0.80 \mathrm{mmol} \mathrm{g}^{-1}$. The preliminary studies of micro-quantities of ${ }^{241} \mathrm{Am},{ }^{233} \mathrm{U}$, and ${ }^{239} \mathrm{Pu}$ radionuclide sorption from aqueous solutions with phosphorylated textile demonstrated the high efficiency.

Keywords: phosphorylated cotton cellulose fabric; mercerisation; sorption; static exchange capacity; copper; americium; uranium; plutonium

\section{Introduction}

Cellulose is one of the most common natural linear syndiotactic homopolymers. Cellulose is formed by glucopyranose units linked through $\beta-(1,4)$-glycosidic bonds. Due to the free hydroxyl groups being linked with a pyranose ring, it is possible to carry out chemical reactions typical for primary and secondary alcohols. Interactions that do not lead to the destruction of the pyranose ring and retain the original structure of the polymer are mainly used, such as the formation of ethers or esters, carboxylation, sulphonation, phosphorylation, and amination [1-5]. When modifying cellulose by introducing new functional groups, one can achieve a cellulose-based compound with new properties and many possible applications. For example, modified cellulose materials are widely used in water filtration technologies, heavy metal sorption processes, and the development of new non-biodegradable products for medicine and fire-retardant materials. [6-14]. A lot of research focuses on phosphorylated cellulose. First, phosphorus-containing groups are introduced and then linked through covalent bonds to the cellulose molecule by treating it with phosphorus-containing compounds, such as $\mathrm{P}_{2} \mathrm{O}_{5}, \mathrm{PCl}_{5}, \mathrm{PCl}_{3}, \mathrm{POCl}_{3}$, and $\mathrm{H}_{3} \mathrm{PO}_{4}[3,5,14-17]$. However, the studies focusing on the phosphorylation process of preliminary mercerized cotton fabric are relatively sparse. Preliminary mercerization of cellulose significantly increases its chemical activity in the etherification processes and improves sample wettability, associated with the sliding effect and smoothness of 
the cellulose fibers, and reduces the edge angle of wetting. Mercerization improves the absorptive properties of the fabric and makes treatment with various solutions easier.

After our samples were treated with $\mathrm{NaOH}$ followed by washing, the partial process of protonation-deprotonation occurred, resulting in surface hydrophilization with an increase in the hydrophilic-lipophilic balance of the fabric. The phosphorylated mercerized cotton materials can be used as active and easily impregnable sorbents in filters, bases for applying defined compositions to a material's surface, and disinfecting agents $[18,19]$. The development of special flushable compositions allows reusing the fabric after it depletes its disinfecting abilities.

We report new results of an elaborate study of phosphorylated mercerized cotton cellulose properties in the present work.

\section{Materials and Methods}

\subsection{Cotton Cellulose Fabric Treatment}

Commercially available mercerized cotton cellulose fabric (Moscow, Russia) with the relative density of $390 \pm 9 \mathrm{~g} / \mathrm{m}^{2}$, plain-weave texture, fiber diameter $250 \pm 30 \mu \mathrm{m}$, and gage $700 \pm 50 \mu \mathrm{m}$ was used. Mercerization of cotton fabric in production was carried out by short-term processing of the fabric with a concentrated $\mathrm{NaOH}$ (BioXtra, $\geq 98 \%$ (acidimetric), pellets (anhydrous)) solution under tension in the cold, followed by rinsing with hot and cold water.

The dried fabric samples containing no more than $10 \%$ of moisture were treated with $2.80 \mathrm{~mol} \mathrm{~L}^{-1}$ urea solution (Merck, GR for analysis ACS, Reag. Ph Eur) and phosphoric acid (ACS reagent, $\geq 85 \mathrm{wt}$. $\%$ in $\mathrm{H}_{2} \mathrm{O}$ ) (the concentration was in the range of 0.200 to $2.403 \mathrm{~mol} \mathrm{~L}^{-1}$ ) at $80{ }^{\circ} \mathrm{C}$ for $1 \mathrm{~h}$ (the ratio of «sample» to «liquid» was 1:10). The treated samples were each squeezed to a mass two times greater than the dry sample mass and dried at $70{ }^{\circ} \mathrm{C}$ for at least $5 \mathrm{~h}$. After drying, the samples were heated at $145-150{ }^{\circ} \mathrm{C}$ for $1.5 \mathrm{~h}$. After the phosphorylation process, the samples were washed three times with hot and cold distilled water and were treated with the $0.10 \mathrm{~mol} \mathrm{~L}^{-1} \mathrm{HCl}$ (ACS reagent, 37\%) solution at room temperature for $1 \mathrm{~h}$. Then, the samples were washed three times with cold distilled water again and were dried at $70{ }^{\circ} \mathrm{C}$ for at least $5 \mathrm{~h}$.

\subsection{Phosphorus Content Determination}

The phosphorus content in cotton fabric before and after phosphorylation was determined by the spectrophotometric method based on the color intensity of the Sn(II) reduced phosphorus molybdenum complex. To convert the phosphorus in the samples to phosphate ions, approximately $500 \mathrm{mg}$ of each sample was treated with a $25 \mathrm{~mL}$ hot mixture consisting of 3 volumes of concentrated sulfuric acid (ACS reagent, 95.0-98.0\%) and 1 volume of $60 \%$ hydrogen peroxide (Dzerzhinsk, Nizhny Novgorod region). When placed in the solution, the samples dissolved completely, and the release of gases accompanied the reaction. After that, the solution was heated at $175^{\circ} \mathrm{C}$ for $1 \mathrm{~h}$ to decompose the unreacted excess of hydrogen peroxide and then transferred into a flask and diluted with distilled water. This kind of treatment and preparation for analysis ensured that all the phosphorus in the phosphorylated sample transformed into phosphoric acid, which allowed determining its content later on. All solutions used and distilled water were thermostabilized beforehand in a water thermostat to $25^{\circ} \mathrm{C}$. Then, $500 \mathrm{~mL}$ of the sample was transferred to a $50 \mathrm{~mL}$ flask and diluted with distilled water to volume. After thorough mixing, $2 \mathrm{~mL}$ of $2 \%$ sulfurous ammonium molybdate $\left(\mathrm{NH}_{4}\right)_{2} \mathrm{MoO}_{4}$ (Sigma Aldrich, $99.98 \%$ trace metals basis) was added, and $0.200 \mathrm{~mL}$ of $3.5 \% \mathrm{SnCl}_{2}$ (Sigma Aldrich, reagent grade, $98 \%$ ) was added after $5 \mathrm{~min}$. The solution was mixed at $25^{\circ} \mathrm{C}$ for $15 \mathrm{~min}$. The optical density of the blue phosphor-molybdenum-reduced complex was detected at a wavelength of $700 \mathrm{~nm}$ (a $5.00 \mathrm{~cm}$ thick cell was used). The experimental molar absorption coefficient for this complex was found to be equal to $\varepsilon_{700 \mathrm{~nm}}=(2.485 \pm 0.023) \times 10^{4} \mathrm{~cm}^{-1} \mathrm{~L} \mathrm{~mol}^{-1}$. According to the previously obtained calibration graph, the phosphorus content in fabric was determined as $\mathrm{mmol} \mathrm{g}^{-1}$ or mass percentages. 


\subsection{Infrared Spectroscopy}

The samples were analyzed on the FTIR (FT-02, INFRALUM, Lumex, St. Petersburg, Russia) spectrometer in the range of $400-4000 \mathrm{~cm}^{-1}$. To do so, $200-300 \mathrm{mg}$ of the fabric samples were thoroughly ground with twice recrystallized KBr (Sigma Aldrich, FT-IR grade, $\geq 99 \%$ trace metals basis) to obtain a homogeneous mixture with a $0.5 \%$ cellulose material mass fraction.

\subsection{Acid-Base Titration}

The acid-base titration of the phosphorylated mercerized cotton cellulose was carried out through potentiometric titration with $0.100 \mathrm{~mol} \mathrm{~L}^{-1} \mathrm{NaOH}$ using the $\mathrm{pH}$ meter («ECOTEST 120», Econix, Moscow, Russia) (glass electrode combined with silver chloride reference electrode).

\subsection{Tensile Strength}

Tensile testing was performed on a Zwick Roell Z010 (Zwick/Roell, Germany) setup. The width of the sample was shown to be $20 \mathrm{~mm}$, thickness $-0.70 \mathrm{~mm}$, preload value$0.10 \mathrm{~N}$, stretching speed $-20 \mathrm{~mm} / \mathrm{min}$. The standard maximum of the breaking force was measured until at least 5 reproducible results were obtained. The results were processed using t-test statistics.

\subsection{Sorption Characteristics}

The sorption characteristics of the samples were determined by studying the sorption process of macro-quantities of $\mathrm{Cu}^{2+}$ and $\mathrm{UO}_{2}{ }^{2+}$ and micro-quantities of ${ }^{241} \mathrm{Am},{ }^{233} \mathrm{U}$, and ${ }^{239} \mathrm{Pu}$ radionuclides.

Sorption of $\mathrm{Cu}^{2+}$ and $\mathrm{UO}_{2}{ }^{2+}$

The sorption properties of the samples were studied on a model of $\mathrm{Cu}^{2+}$ and $\mathrm{UO}_{2}{ }^{2+}$ sorption from $\mathrm{CuSO}_{4}$ (anhydrous, powder, $\geq 99.99 \%$ trace metals basis) (the concentration was in the range of $\left.1-200 \mathrm{mmol} \mathrm{L}^{-1}\right)$ and $20 \mathrm{mmol} \mathrm{L}^{-1} \mathrm{UO}_{2}\left(\mathrm{NO}_{3}\right)_{2}(99.9 \%$, Russia) solutions. About $0.5 \mathrm{~g}$ of the sample was soaked in a pH 3.0 solution of sulfuric acid at $20^{\circ} \mathrm{C}$ for 5 days while stirring (the ratio of «sample» to «liquid» was 1:50). The $\mathrm{pH}$ changes after sorption were detected to be no more than 0.5 . The $\mathrm{Cu}^{2+}$ concentration before and after soaking the sample in the solution was determined spectrophotometrically with the Cary Varian 100 device based on the ammonia complex color intensity at $\lambda=630 \mathrm{~nm}$ in the presence of a 1000-fold excess of the ligand $\left(\varepsilon_{630}=69.5 \pm 0.5 \mathrm{~cm}^{-1} \mathrm{~L} \mathrm{~mol}^{-1}\right)$.

The $\mathrm{UO}_{2}{ }^{2+}$ concentration in the solution was determined spectrophotometrically on the Shimadzu UV 3100 (Shimadzu Corporation, Japan) device based on the color intensity at $\lambda=420 \mathrm{~nm}$. The values of the static capacity were calculated using the following equation:

$$
S E C=\frac{\left(C_{0}-C_{e q}\right) \cdot V_{s}}{m_{t}}
$$

where SEC-static exchange capacity for copper or uranyl ions, $\mathrm{mmol} \mathrm{g}^{-1} ; C_{0}$-initial concentration of copper or uranyl ions in the solution, $\mathrm{mmol} \mathrm{L}^{-1} ; C_{e q}$ - equilibrium concentration of copper or uranyl ions in the solution, $\mathrm{mmol} \mathrm{L}^{-1} ; V_{s}$-the volume of the solution, $\mathrm{L} ; m_{t}$-sample mass, $\mathrm{g}$.

\subsection{Sorption of Radionuclides ${ }^{241} \mathrm{Am},{ }^{233} \mathrm{U}$, and ${ }^{239} \mathrm{Pu}$}

Caution! ${ }^{241} \mathrm{Am},{ }^{233} \mathrm{U}$, and ${ }^{239} \mathrm{Pu}$ are highly radioactive isotopes and require specially equipped facilities for safe work.

About $0.1 \mathrm{~g}$ of the fabric sample (precision of weighing $- \pm 0.0001 \mathrm{~g}$ ) was soaked in a prepared solution at $20^{\circ} \mathrm{C}$ for $48 \mathrm{~h}$ while stirring (the ratio of «sample» to «liquid» was 1:200). The specific activity of ${ }^{241} \mathrm{Am},{ }^{233} \mathrm{U}$, or ${ }^{239} \mathrm{Pu}$ radionuclides was determined using the filtrate above the solid phase. 
The sorption of ${ }^{241} \mathrm{Am}$ and ${ }^{233} \mathrm{U}$ was tested on Moscow tap water with the following composition: $\mathrm{mg} \mathrm{L}^{-1}: \mathrm{Na}^{+}, 6-8 ; \mathrm{K}^{+}, 4-5 ; \mathrm{Mg}^{2+}, 15-17 ; \mathrm{Ca}^{2+}, 52-56 ; \mathrm{Cl}^{-}, 6-8 ; \mathrm{SO}_{4}{ }^{2-}, 36-38 ; \mathrm{HCO}_{3}{ }^{-}$, 200-205; total mineral content, 310-330; hardness, 3.6-3.8 $\mathrm{mmol} \mathrm{L}^{-1} ; \mathrm{pH}=7.3-7.8$. The appropriate amount of the corresponding radionuclide (about $10^{5} \mathrm{~Bq} \mathrm{~L}^{-1} \approx 4.3 \mathrm{mg} \mathrm{L}^{-1}{ }^{233} \mathrm{U}$ ) was added to the liquid phase and kept for $120 \mathrm{~h}$ to establish hydrolytic equilibrium between the radioactive and inactive components of the solution. The solution for investigating plutonium sorption contained $1.0 \mathrm{~mol} \mathrm{~L}^{-1} \mathrm{HNO}_{3}$ and about $10^{6} \mathrm{~Bq} \mathrm{~L}{ }^{-1}{ }^{239} \mathrm{Pu}$ and was prepared by dissolving $1.0 \mathrm{mg}\left[\mathrm{N}\left(\mathrm{CH}_{3}\right)_{4}\right]_{2} \mathrm{Pu}\left(\mathrm{NO}_{3}\right)_{6}$ in an aliquot of $3.0 \mathrm{~mol} \mathrm{~L}^{-1} \mathrm{HNO}_{3}$ and diluting it with water. The fabric samples were added to the solution and soaked in it. After the sorption equilibrium was reached, the partition coefficient was calculated with the following equation:

$$
K_{d}=\frac{A_{0}-A_{e q}}{A_{e q}} \cdot \frac{V_{s}}{m_{t}}
$$

where $K_{d}$-partition coefficient, $\mathrm{ml} \mathrm{g}^{-1} ; A_{0}$ and $A_{e q}$-initial and equilibrium specific activity of radionuclides, $\mathrm{Bq} \mathrm{L}^{-1} ; V_{S}$-solution volume, $\mathrm{ml} ; m_{t}$-fabric mass, $\mathrm{g}$.

The specific activity of ${ }^{241} \mathrm{Am}$ in solutions was determined by a radiometric method from the intensity of $59 \mathrm{keV} \gamma$-line using an SKS-50M spectrometric complex («Green Star Technologies», Australia). The specific activities of ${ }^{233} \mathrm{U}$ and ${ }^{239} \mathrm{Pu}$ in solutions were determined by an alpha-spectrometric method from the intensities of 4.9 and $5.2 \mathrm{MeV}$ lines, respectively, using a low-background semiconductor alpha spectrometer ALPHA-ARIA («ORTEC», USA).

\section{Results and Discussion}

Both external and structural changes were the results of the phosphorylation process of preliminary mercerized cotton cellulose. The sample had a yellowish color after being heated up to $145^{\circ} \mathrm{C}$, the intensity of which subsequently faded after being washed in hot and cold distilled water. According to the tensile strength test results, the heat treatment did not reduce the sample strength characteristics during phosphorylation in the absence of $\mathrm{H}_{3} \mathrm{PO}_{4}$. The standard maximum tensile strengths for untreated and phosphorylated samples were observed to be equal to $17.2 \pm 0.5$ and $17.9 \pm 0.6 \mathrm{MPa}$. The difference between the statistical error margins indicates that there were no changes in the molecular and supramolecular structure after both mercerization and heat treatment of the cotton fabric. However, even a low concentration $\left(0.20 \mathrm{~mol} \mathrm{~L}^{-1}\right)$ of $\mathrm{H}_{3} \mathrm{PO}_{4}$ caused a decrease in the sample's strength characteristics by almost two times (Figure 1; apparently, it was caused by the changes in the structures of the molecules and their partial destruction, which seemed to increase when increasing the phosphoric acid concentration in the phosphorylating solution). However, it should be noticed that the full destruction of the sample was not observed at $\mathrm{H}_{3} \mathrm{PO}_{4}$ concentration up to $2.403 \mathrm{~mol} \mathrm{~L}^{-1}$.

The results of phosphorus content determination are shown in Table 1.

Table 1 shows a noticeable increase in phosphorus content in the samples, which corresponds to the increased phosphoric acid concentration in the phosphorylating solution. The number of phosphorus-containing groups per $1 \mathrm{~g}$ of the sample increased from 0.179 to $0.950 \mathrm{mmol}$, while the phosphoric acid concentration increased from 0.201 to $2.00 \mathrm{~mol} \mathrm{~L}^{-1}$. However, a further increase in the acid concentration did not increase phosphorus content, which was constant within the margin of statistical error.

For comparison, the unmercerized cotton fabric was phosphorylated, and phosphorus content in it was determined. Unmercerized cotton fabric is less hydrophilic and is more difficult to treat with aqueous solutions. Figure 2 shows the phosphorus content in the phosphorylated mercerized and unmercerized fabrics against the phosphoric acid concentration in the phosphorylating solution. The phosphorus content increased with the increase in the phosphoric acid concentration, for both the mercerized and the unmercerized fabric. However, phosphorus content increased nonlinearly to about $3 \mathrm{wt} . \%$ in the mercerized fabric and $1 \mathrm{wt} . \%$ in the unmercerized fabric. The phosphorus content in the mercerized sample was found to be three times greater than in the unmercerized one. 


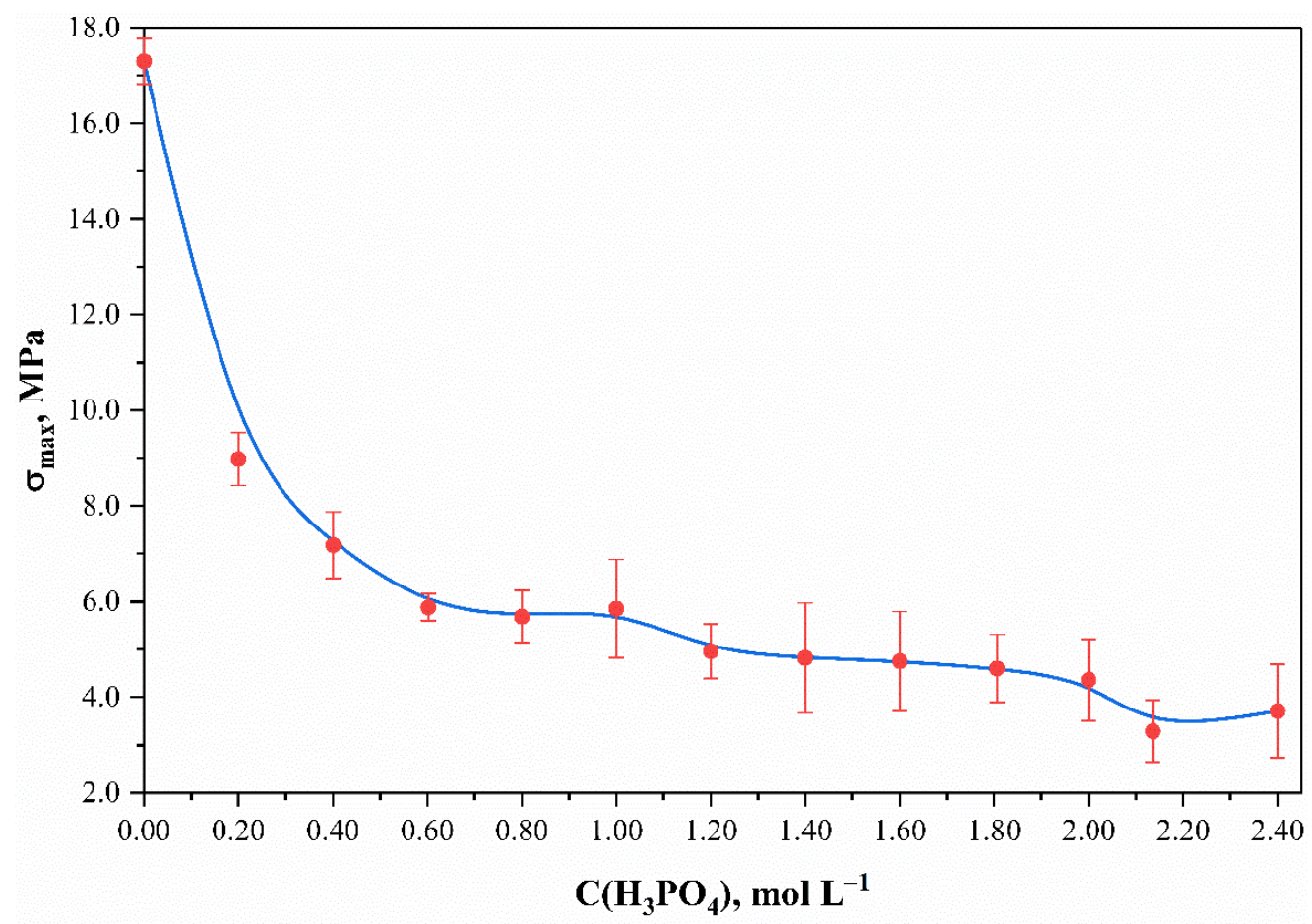

Figure 1. Effect of phosphoric acid content on the standard maximum tensile strength for phosphorylated cotton fabric samples.

Table 1. Results of the phosphorus content determination in the cotton cellulose samples before and after phosphorylation, obtained by the spectrophotometric method based on the color intensity of the reduced phosphorus molybdenum complex.

\begin{tabular}{|c|c|c|c|}
\hline № & $\mathrm{C}\left(\mathrm{H}_{3} \mathrm{PO}_{4}\right), \mathrm{mol} \mathrm{L}^{-1}$ & Content $\mathrm{P}$, wt. $\%$ & $n(\mathrm{P})$ in $1 \mathrm{~g}$ Textile, $\mathrm{mmol} \mathrm{g}^{-1}$ \\
\hline 1 & 0 & $0.062 \pm 0.006$ & $0.0201 \pm 0.0020$ \\
\hline 2 & 0.201 & $0.55 \pm 0.06$ & $0.179 \pm 0.018$ \\
\hline 3 & 0.399 & $1.28 \pm 0.13$ & $0.414 \pm 0.041$ \\
\hline 4 & 0.601 & $1.49 \pm 0.15$ & $0.481 \pm 0.048$ \\
\hline 5 & 0.802 & $1.89 \pm 0.19$ & $0.611 \pm 0.061$ \\
\hline 6 & 1.01 & $2.31 \pm 0.23$ & $0.745 \pm 0.075$ \\
\hline 7 & 1.20 & $2.48 \pm 0.25$ & $0.802 \pm 0.080$ \\
\hline 8 & 1.40 & $2.78 \pm 0.28$ & $0.898 \pm 0.090$ \\
\hline 9 & 1.60 & $2.90 \pm 0.29$ & $0.938 \pm 0.094$ \\
\hline 10 & 1.80 & $2.73 \pm 0.27$ & $0.881 \pm 0.088$ \\
\hline 11 & 2.00 & $2.94 \pm 0.29$ & $0.950 \pm 0.095$ \\
\hline 12 & 2.20 & $2.53 \pm 0.25$ & $0.816 \pm 0.082$ \\
\hline 13 & 2.40 & $2.73 \pm 0.27$ & $0.881 \pm 0.088$ \\
\hline
\end{tabular}




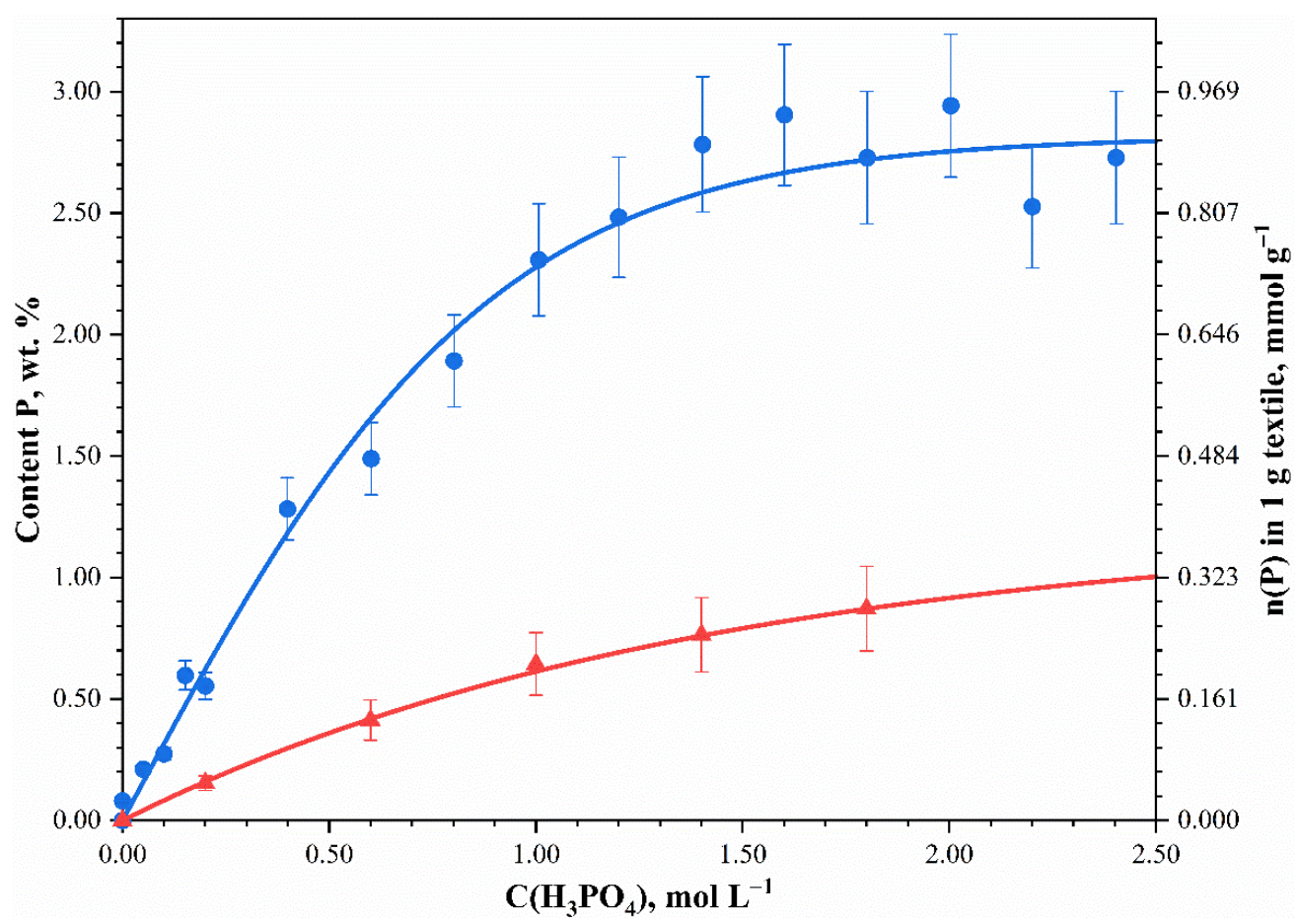

Figure 2. The phosphorus content (wt.\% and mol in $1 \mathrm{~g}$ textile) in the phosphorylated mercerized (circles) and unmercerized (triangles) fabrics versus phosphoric acid concentration in the phosphorylating solution.

The IR spectroscopy results of the mercerized cotton cellulose samples are shown in Figure 3.

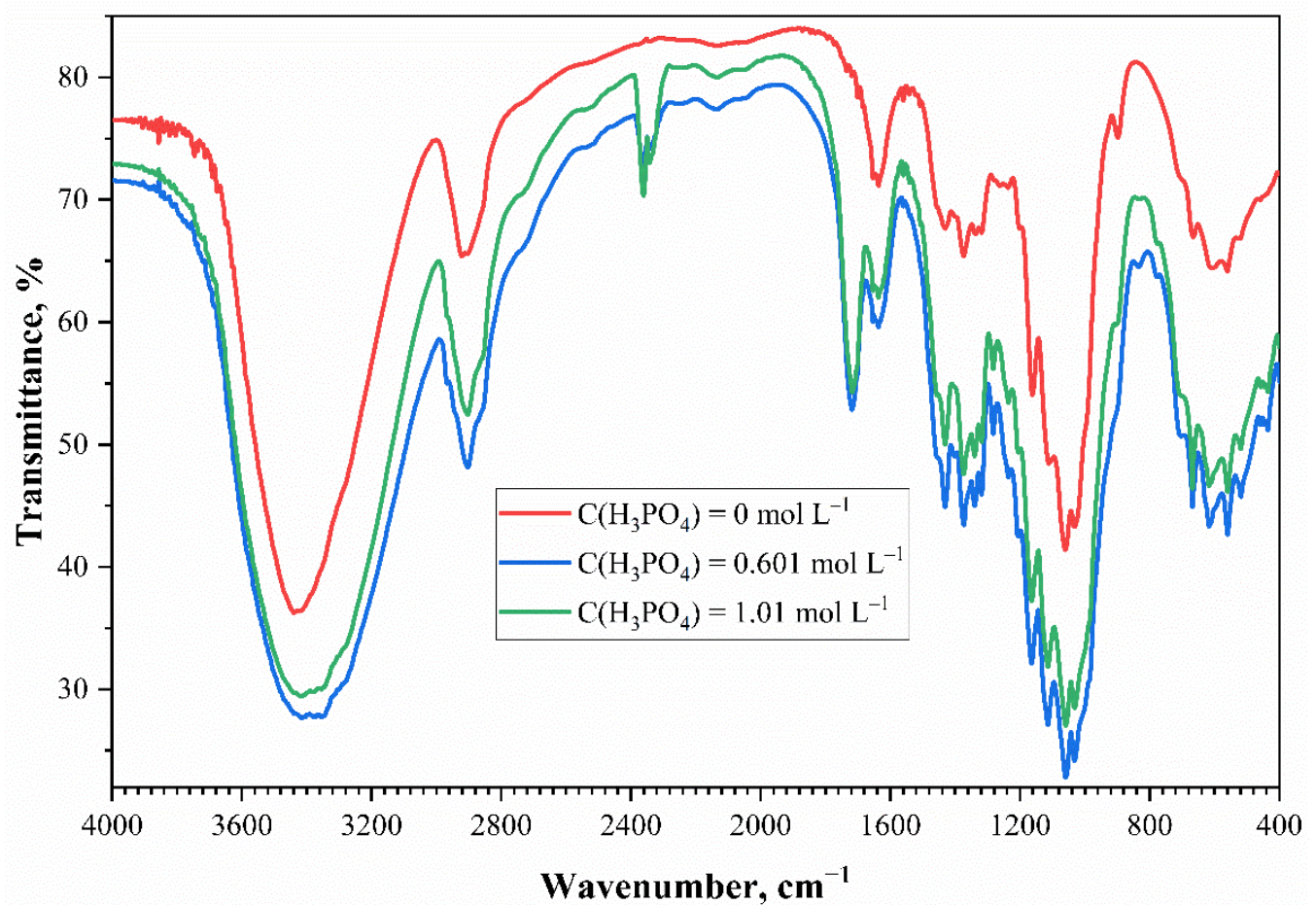

Figure 3. The IR spectrum of the mercerized cotton cellulose and the phosphorylated-cotton, cellulosetreated solutions with different phosphoric acid concentrations. 
According to Suflet and Lehtonen [2,3], a mercerized cotton cellulose sample has specific IR wavenumbers: $\mathrm{O}-\mathrm{H}$ groups stretching vibrations at $3400-3500 \mathrm{~cm}^{-1}, \mathrm{CH}_{2}$-groups at $2800-2900 \mathrm{~cm}^{-1}$, and C-O-C elements of the glycosidic bonds at 1166 and $1115 \mathrm{~cm}^{-1}$. Several additional bands in the IR spectrum of the phosphorylated cotton cellulose were obtained. The absorption band at $1720 \mathrm{~cm}^{-1}$ indicates the presence of the $\mathrm{C}=\mathrm{O}$ groups that were probably formed after the destruction of the pyranose ring and the partial oxidation of cellulose at high temperatures and formation of carbamates [20-23]. Presumably, it means partial oxidation of the sample. The absorption band at $2370 \mathrm{~cm}^{-1}$ belongs to the $\mathrm{P}-\mathrm{H}$ stretching vibrations, the absorption band at $1210 \mathrm{~cm}^{-1}$ to the $\mathrm{P}=\mathrm{O}$ stretching vibrations, and the absorption band at $830 \mathrm{~cm}^{-1}$ to the $\mathrm{P}-\mathrm{O}-\mathrm{C}$ stretching vibrations. The absence of additional bands in the $2800-2900 \mathrm{~cm}^{-1}$ region and the shoulder at $920-1000 \mathrm{~cm}^{-1}$, coming from the $\mathrm{P}-\mathrm{O}-\mathrm{H}$ valence vibrations, indicate the absence of the said functional groups. This was also confirmed by the inability to perform acid-base titration on phosphorylated cotton cellulose. The potentiometric titration curve does not show the expected jump when titrating a crushed sample with a $\mathrm{KOH}$ solution. This fact proves that there were no functional phosphorus-containing groups with hydrogen that could be substituted.

The modified phosphorylated cotton cellulose can be used as a toxic heavy metal sorbent [24-26]. We tested the sorption properties of the obtained phosphorylated cotton cellulose samples using aqueous solutions of copper as an example, since it can be assumed that similar behavior under these conditions would be demonstrated by other divalent metals, such as nickel, cobalt, iron, lead, and strontium. The sorption properties of the phosphorylated cotton cellulose were studied by using $\mathrm{Cu}^{2+}$ sorptive properties in solutions with different concentrations as a reference $\left(\mathrm{pH}=3.0, \mathrm{t}=20^{\circ} \mathrm{C}\right)$. The obtained data demonstrate a significant increase in the sorption capacity in the presence of the phosphorus-containing groups. Furthermore, the shapes of the adsorption isotherms and their non-linearity indicate a complicated mechanism of the adsorption process. Presumably, chemosorption occurs on the surface due to complexation along with the $\mathrm{Cu}^{2+}$ physical adsorption. The obtained data were described by the Langmuir monomolecular adsorption model (Figure 4). The plateau corresponds to the saturation of sorption centers and formation of a monomolecular layer according to the equation:

$$
S E C=S E C_{\infty} \cdot \frac{K \cdot C\left(\mathrm{Cu}^{2+}\right)}{1+K \cdot C\left(\mathrm{Cu}^{2+}\right)}
$$

where $S E C$ - static exchange capacity, $\mathrm{mmol} \mathrm{g}^{-1} ; S E C_{\infty}$-maximum static exchange capacity, mmol g${ }^{-1} ; K$-exchange equilibrium constant-the ratio of sorption rate constants to desorption rate constants, $\mathrm{L} \mathrm{mmol}^{-1} ; C\left(\mathrm{Cu}^{2+}\right)$-copper ions concentration in the solution, mmol L ${ }^{-1}$.

However, a further increase in SEC along with an increase of the sorbed $\mathrm{Cu}^{2+}$ concentration indicates the polymolecular nature of sorption. In this case, the rise of the sorption isotherm at more than $125 \mathrm{mmol} \mathrm{L}^{-1}$ of $\mathrm{Cu}^{2+}$ is explained by the sorption of additional copper amounts and the appearance of the second and subsequent adsorption layers, and the occurrence of chemosorption.

Thereby it is appropriate to compare the maximum static exchange capacity of the monomolecular layers $S E C_{\infty}$ of different phosphorylated cotton cellulose samples (Figure 5). 


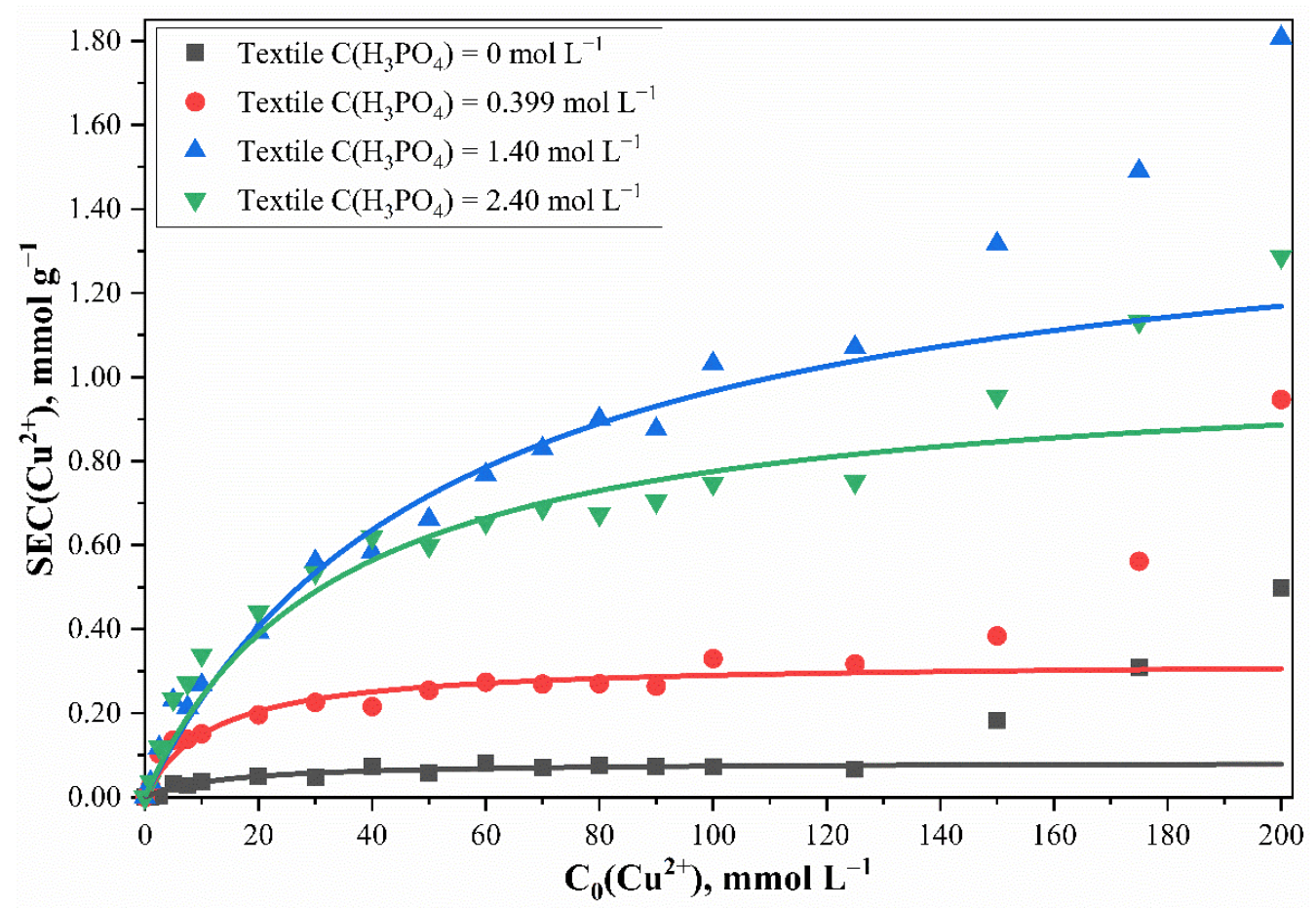

Figure 4. $\mathrm{Cu}^{2+}$ sorption isotherms of cotton cellulose samples phosphorylated with phosphoric acid solutions of different concentrations. Points—experimental data; lines—calculated values according to the Langmuir equation. The temperature of the solutions during sorption experiments was $\mathrm{t}=20^{\circ} \mathrm{C}$.

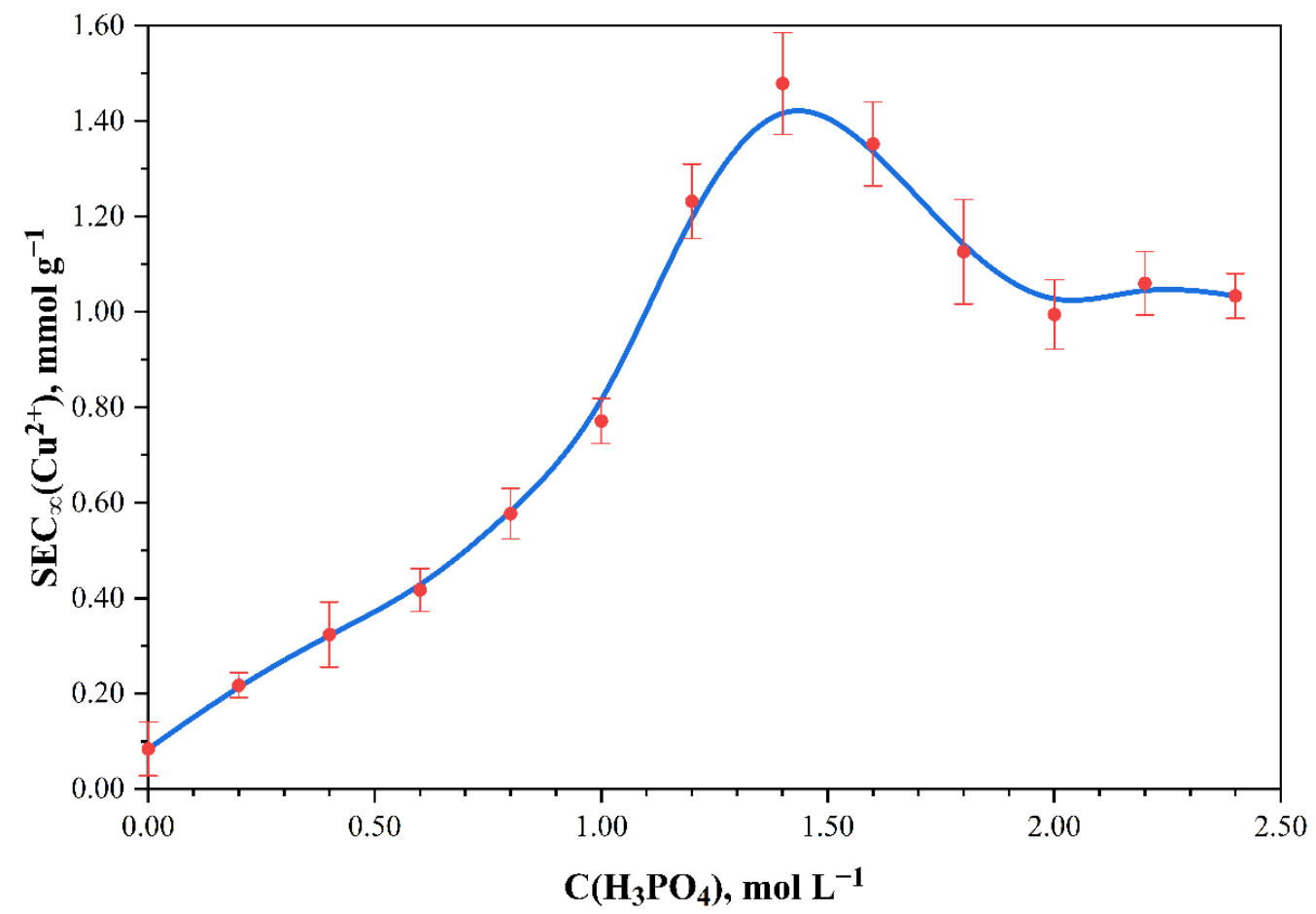

Figure 5. Effect of phosphoric acid concentration on the maximum static exchange capacity $S E C_{\infty}$ $\left(\mathrm{t}=20^{\circ} \mathrm{C}\right)$ of phosphorylated cotton cellulose samples related to $\mathrm{Cu}^{2+}$. 
It is clear that sample phosphorylation, even with low concentrations of phosphoric acid, led to an increase in the maximum sorption capacity. The results confirm that the phosphate groups were added to the monomer units of the cotton cellulose. In addition, the initial part of the curve shows an increase in the $\mathrm{Cu}^{2+}$ sorption capacity and an increase in the concentration of $\mathrm{H}_{3} \mathrm{PO}_{4}$ in the phosphorylating solution. The $S E C_{\infty}$ maximum $\left(1.48 \pm 0.11 \mathrm{mmol} \mathrm{g}^{-1}\right)$ was observed with $1.40 \mathrm{~mol} \mathrm{~L}^{-1}$ of $\mathrm{H}_{3} \mathrm{PO}_{4}$. The maximum sorption capacity did not change up to $1.80 \mathrm{~mol} \mathrm{~L}^{-1}$ of $\mathrm{H}_{3} \mathrm{PO}_{4}$ within the margin of error. A further increase in $\mathrm{H}_{3} \mathrm{PO}_{4}$ concentration caused a significant decrease in $S E C_{\infty}$. Furthermore, considering a dependence between amount of $\mathrm{Cu}^{2+}$ absorbed and phosphorus content, it can be concluded that a linear correlation exists (Figure 6). $\mathrm{Cu}^{2+}$ coordinated in the ratio of $n\left(\mathrm{Cu}^{2+}\right): n(\mathrm{P})=1: 1$ with no more than $0.80 \mathrm{mmol} \mathrm{g}^{-1}$ of phosphorus content. The exchange equilibrium constant for the samples with phosphorus content no more than $0.80 \mathrm{mmol} \mathrm{g}^{-1}$ was found to be $0.0803 \pm 0.0087 \mathrm{~L} \mathrm{mmol}^{-1}$. For the samples with the phosphorus content of $0.80 \mathrm{mmol} \mathrm{g}^{-1}$ and higher, the exchange constant was equal to $0.0331 \pm 0.0077 \mathrm{~L} \mathrm{mmol}^{-1}$. When studying the sorption properties of the phosphorylated cotton fabric with phosphorus content exceeding $0.80 \mathrm{mmol} \mathrm{g}^{-1}$, it was discovered that $\mathrm{Cu}^{2+}$ sorption increased, and the $n\left(\mathrm{Cu}^{2+}\right): n(\mathrm{P})=1: 1$ ratio was no longer true. This can be explained by the bidenticity of phosphorus-containing groups and their ability to coordinate more metal ions than in the case of a 1:1 ratio. This proportionality indicates a complexation reaction and the chemical nature of the sorption.

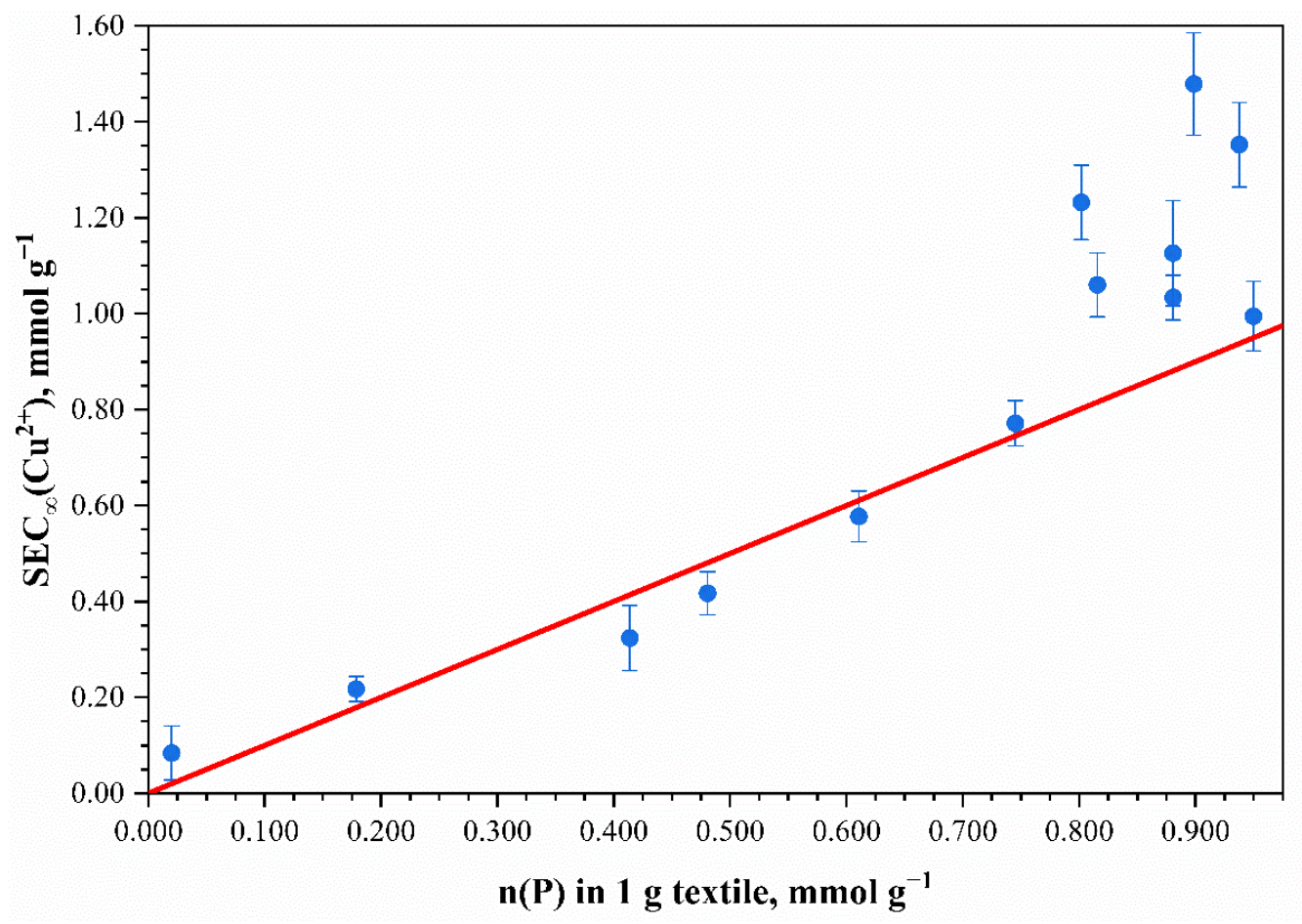

Figure 6. Effect of phosphorus content in mercerized phosphorylated cotton cellulose on the maximum static exchange capacity $S E C_{\infty}\left(t=20^{\circ} \mathrm{C}\right)$ related to $\mathrm{Cu}^{2+}$. Points-experimental data; the line corresponds to the $n\left(\mathrm{Cu}^{2+}\right): n(\mathrm{P})=1: 1$ ratio.

Sorption of uranyl ions, americium(III), and plutonium(IV) was studied, since they are usually present in radioactive waste and are the most radiotoxic elements, primarily due to the long half-lives of their main isotopes present in radioactive waste. In addition, the obtained data can help to predict the general sorption behavior for all f-elements in their specified oxidation states. 
The isotherm of uranyl ions sorption was obtained from a sample phosphorylated with $0.802 \mathrm{~mol} \mathrm{~L}^{-1} \mathrm{H}_{3} \mathrm{PO}_{4}$ solution (phosphorus content-1.89 $\pm 0.19 \mathrm{wt} . \%$; $n(\mathrm{P})=0.611 \pm 0.061 \mathrm{mmol} \mathrm{g}^{-1}$ ) (Figure 7).

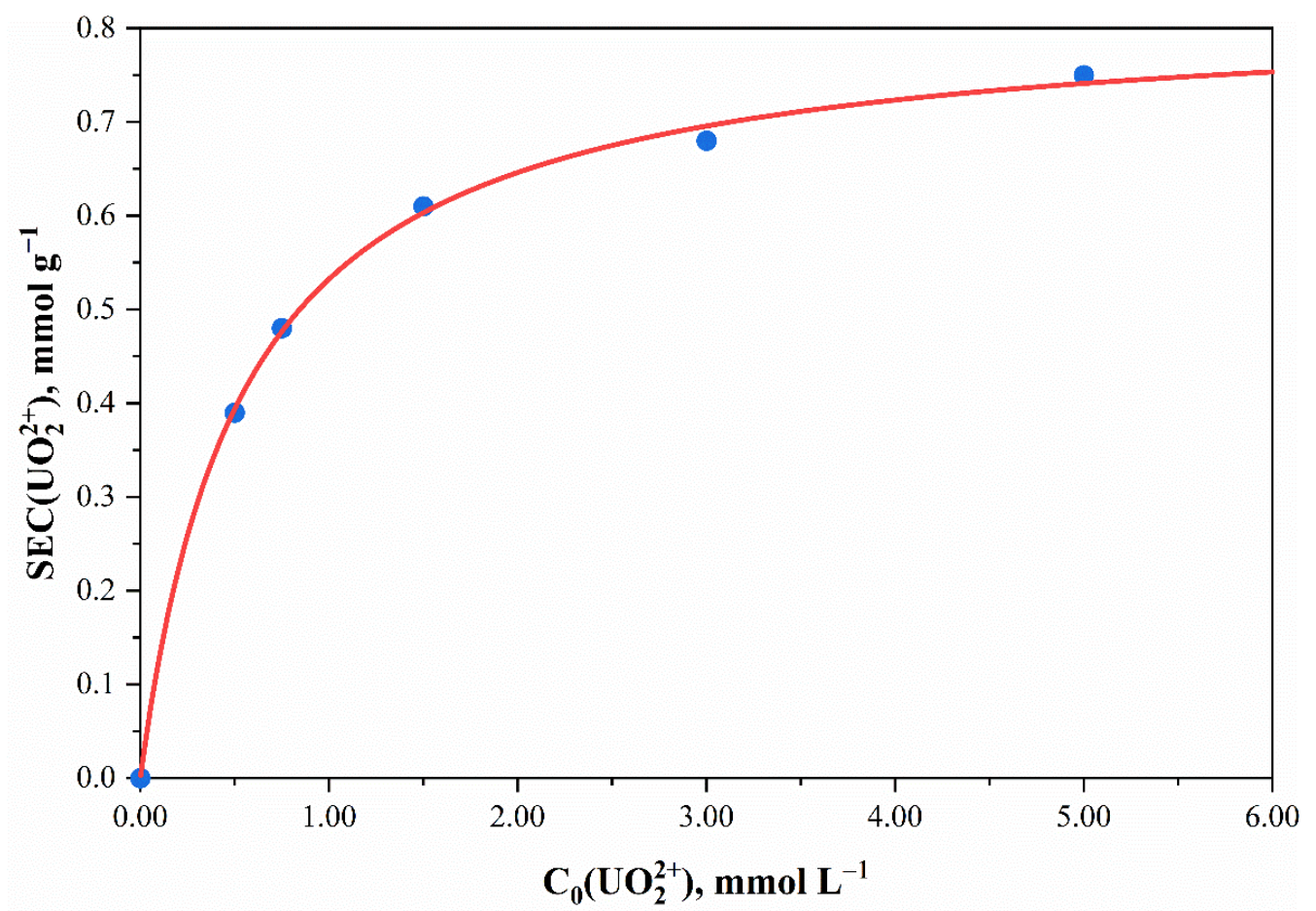

Figure 7. $\mathrm{UO}_{2}{ }^{2+}$ sorption isotherm of cotton cellulose samples phosphorylated with $0.802 \mathrm{~mol} \mathrm{~L}^{-1}$ $\mathrm{H}_{3} \mathrm{PO}_{4}$ solution (phosphorus content-1.89 \pm 0.19 wt. $\% ; n(\mathrm{P})=0.611 \pm 0.061 \mathrm{mmol} \mathrm{g}^{-1}$ ). Pointsexperimental data; lines - calculated values in accordance with the Langmuir equation. The temperature of the solutions during sorption experiments was $\mathrm{t}=20^{\circ} \mathrm{C}$.

The obtained experimental data are well described by the Langmuir equation. The maximum static exchange capacity $\left(S E C_{\infty}\right)$ and the exchange equilibrium constant $(\mathrm{K})$ for the uranyl ions sorption by the phosphorylated fabric sample were $0.822 \pm 0.014 \mathrm{mmol} \mathrm{g}^{-1}$ and $1.844 \pm 0.11 \mathrm{~L} \mathrm{mmol}^{-1}$. The high values of the exchange constants and the convex shape of the sorption isotherms indicate that the uranyl ions sorption by phosphorylated cellulose samples is highly selective.

The dependence of the static exchange capacity $\mathrm{UO}_{2}{ }^{2+}$ on the phosphorus content in the fabric samples is shown in Figure 8.

The presented results (Figure 8) show that an increase of phosphorus content in the samples increased the capacity of the uranyl ions. This indicates an increase in the number of ionogenic groups in the composition of sorbents when using more concentrated phosphoric acid solutions in the phosphorylation process. Higher absolute values of static exchange capacity for uranyl ions than static exchange capacity for copper are apparently associated with the formation of stronger uranium compounds with phosphate groups on cellulose.

The distribution coefficient's $\left(K_{d}\right)$ dependence for ${ }^{241} \mathrm{Am},{ }^{233} \mathrm{U}$, and ${ }^{239} \mathrm{Pu}$ radionuclides on the phosphorus content in the phosphorylated cellulose samples is shown in Figure 9 . 


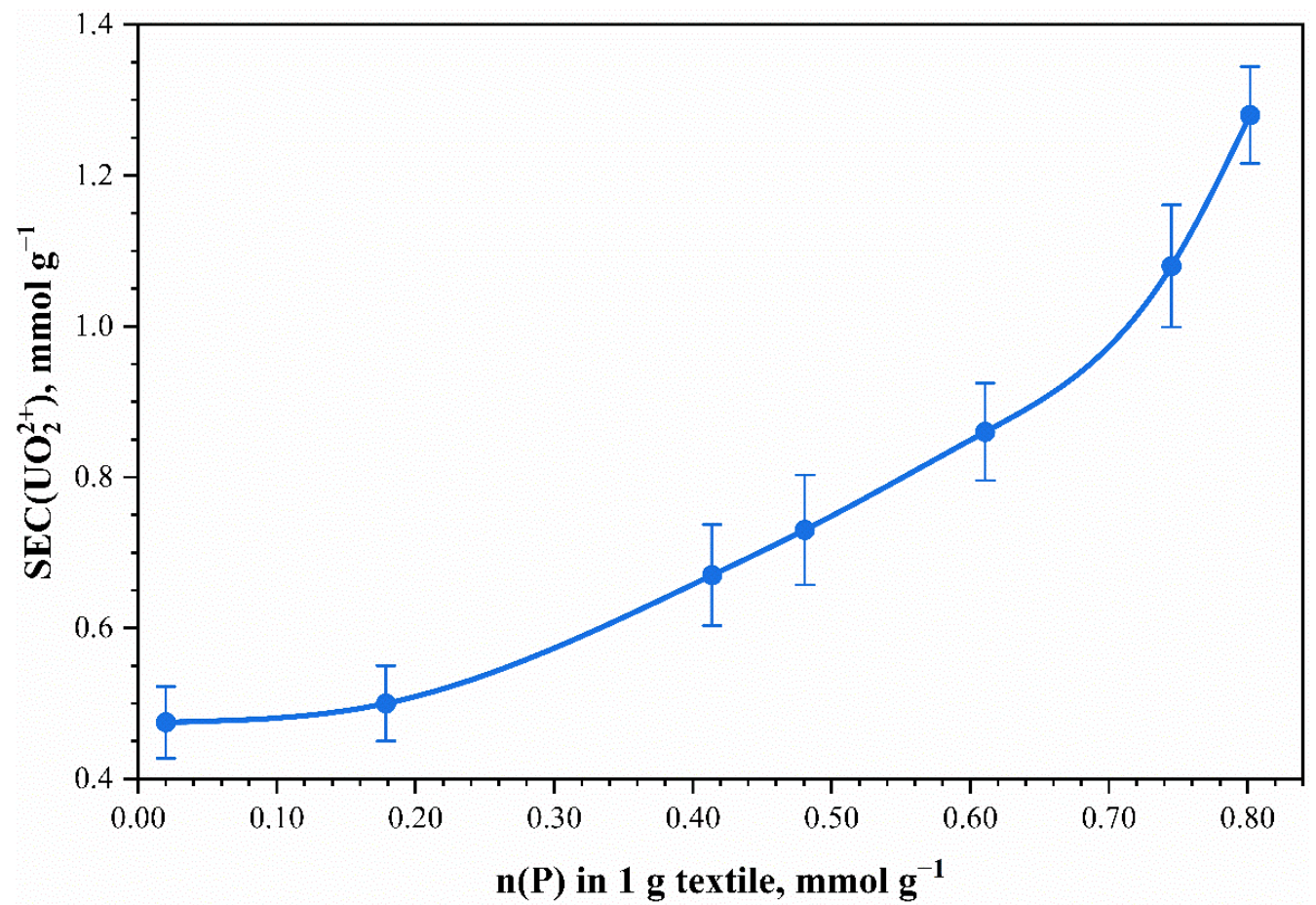

Figure 8. Effect of phosphorus content in mercerized phosphorylated cotton cellulose on the static exchange capacity SEC from $20 \mathrm{mmol} \mathrm{L}{ }^{-1} \mathrm{UO}_{2}{ }^{2+}$ solutions. Points-experimental data; the line corresponds to the ratio $n\left(\mathrm{Cu}^{2+}\right): n(\mathrm{P})=1: 1$. The temperature of the solutions during sorption experiments was $\mathrm{t}=20^{\circ} \mathrm{C}$.

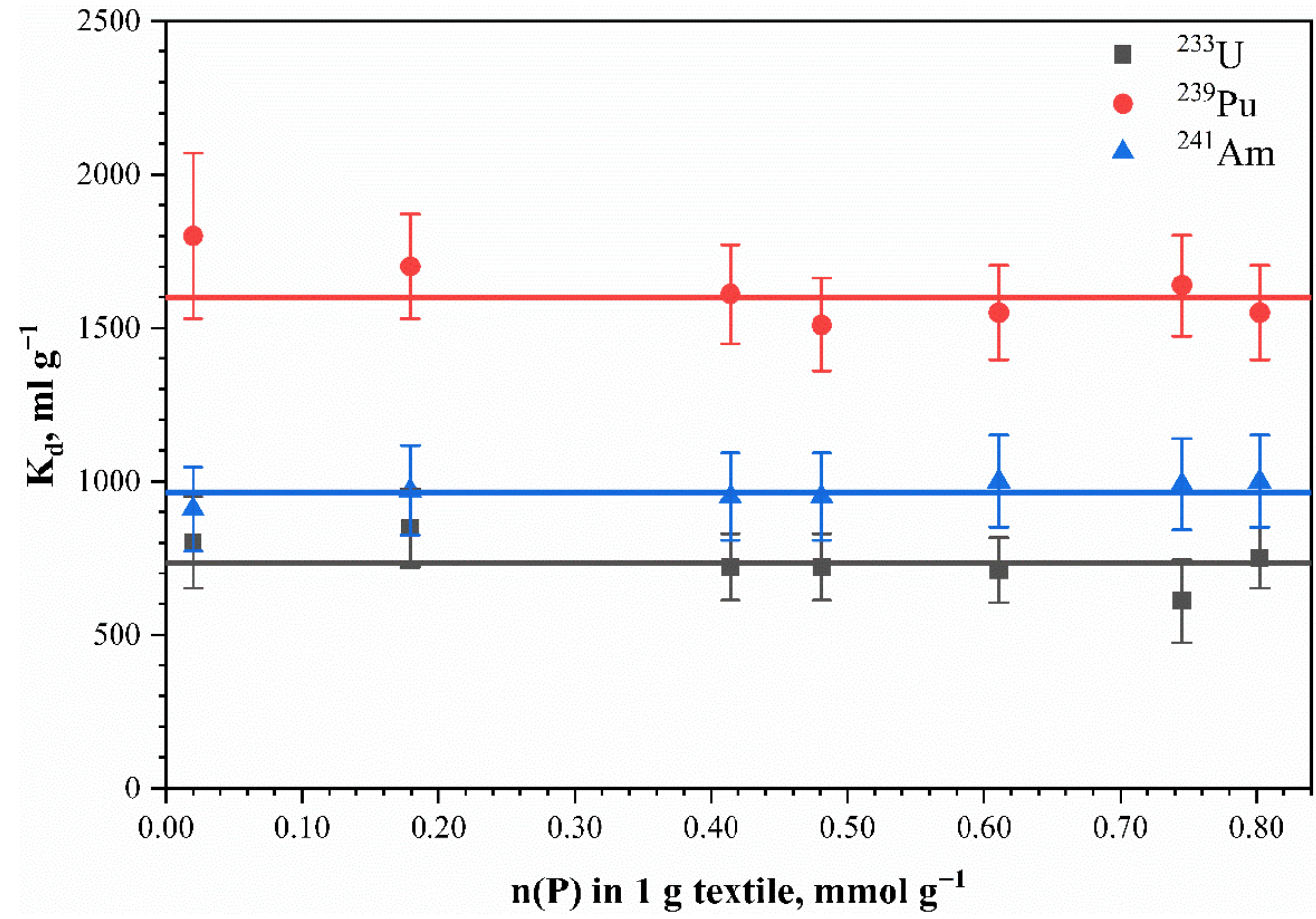

Figure 9. Effects of phosphorus content in mercerized phosphorylated cotton cellulose on the partition coefficient for different radionuclides. Points-experimental data; lines correspond to the partition coefficients. The sorption of ${ }^{241} \mathrm{Am}$ and ${ }^{233} \mathrm{U}$ was tested on Moscow tap water; sorption of ${ }^{239} \mathrm{Pu}$-with $1.0 \mathrm{~mol} \mathrm{~L}^{-1} \mathrm{HNO}_{3}$ solution. 
The results presented in Figure 9 demonstrate no statistically significant change in ${ }^{241} \mathrm{Am},{ }^{233} \mathrm{U}$, and ${ }^{239} \mathrm{Pu}$ radionuclide sorption in relation to increasing the phosphorus content in the fabric sorbents. The average partition coefficient $\left(K_{d}\right)$ values for radionuclides were $965 \pm 13,1600 \pm 32$, and $734 \pm 25 \mathrm{~mL} \mathrm{~g}^{-1}$, respectively. In the case of ${ }^{241} \mathrm{Am}$ and ${ }^{233} \mathrm{U}$, the observed effect can be explained with their presence in tap water in hydrolyzed forms, i.e., corresponding hydroxides or radiocolloids. Sorption of these forms of radionuclides occurs due to physical adsorption on the sorbent surface and does not depend on the degree of phosphorylation of the cellulose. The absence of the effect of the phosphorus content on the sorption of ${ }^{239} \mathrm{Pu}$ may have been due to the high complexing ability of phosphate groups for $\mathrm{Pu}^{4+}$ ions. In this case, almost complete sorption (more than 99\%) of microquantities of plutonium from the acidic solution occurred despite the change in ionogenic groups' concentrations in the sorbent. It should be noted that physical adsorption of hydrolyzed and polymeric forms of plutonium (which can be formed in $1.0 \mathrm{~mol} \mathrm{~L}^{-1}$ $\mathrm{HNO}_{3}$ ) can occur.

The research results demonstrating such a significant static exchange capacity of uranyl ions provide the possibility of using pre-mercerized phosphorylated cotton fabric as a sorbent of other radioactive actinides. This promising sorbent with pre-combustion allows the compaction of ash into cement matrixes and the disposal of radioactive waste.

\section{Conclusions}

Mercerized cotton fabric is a cheap, commercially available raw material used in the production of woven materials for various purposes. Therefore, it presents the possibility to create modified materials with other functional groups in order to achieve desired physicochemical properties. Phosphorylation of cotton cellulose fabric reduces its strength, and high concentrations of phosphoric acid in the phosphorylating solution (more than $2.40 \mathrm{~mol} \mathrm{~L}^{-1}$ ) lead to significant destruction of the fabric, which deprives it of advantages in application and regeneration over powdered cellulose.

The study of mercerized cotton cellulose samples by IR spectroscopy and their potentiometric titration showed that the $\mathrm{P}=\mathrm{O}$ and $\mathrm{C}-\mathrm{O}-\mathrm{P}$ functional groups are present in the structure of the modified cellulose. The absence of a significant increase in the $\mathrm{Pu}^{4+}$ sorption with an increase in phosphorus content may indicate the absence of a hydroxyl group on the phosphorus atom. This behavior is observed in mono- and dialkyl phosphoric acids that form extremely strong complexes with tetravalent f-elements ions. Our sorption study of microquantities of actinides in different oxidation states from tap water shows that a noticeable amount of bicarbonate ions levels out the difference in the sorption behavior of the studied elements. It allows us to assume that significant contributions by physical sorption and the formation of radiocolloids occurred. In the case of $\mathrm{Pu}^{4+}$ sorption, the typical pattern of the tetravalent f-elements' ions' interaction with trialkyl phosphates was observed. That confirms the assumption that phosphoryl groups were present in the modified cellulose in a form close to trialkyl phosphate.

Data analysis on the static exchange capacity of pre-mercerized phosphorylated cellulose indicates a complex polymolecular adsorption mechanism, which can be described by the Langmuir equation. It was found that coordination of a copper ion occurs by a single phosphorus-containing group $\left(n\left(\mathrm{Cu}^{2+}\right): n(\mathrm{P})=1: 1\right)$ with $0.80 \mathrm{mmol} \mathrm{g}^{-1}$ of phosphorus in the sample.

The mercerization process is also simple and easily feasible at the place of production. Hence, the obtained results are of interest for developers of new woven materials with high phosphorus content and the ability to absorb heavy and carcinogenic metals. In addition, the discovered high sorptive ability of the studied fabric to uranyl ion opens up the possibility of burial of radioactive actinides by ash cementation after complete combustion of the spent sorbent.

The obtained results make it possible to implement phosphorylated cellulose as a material suitable for collecting and removing small volumes of technological solutions containing valuable or hazardous metals for recuperation or waste disposal. 
Author Contributions: Investigation, R.S., A.P., A.S. (Alexander Seliverstov), A.S. (Alexey Shapagin), V.M.; data curation-R.S., A.P., A.F.; writing-original draft preparation, R.S., A.F.; writing-review and editing, R.S., A.F.; visualization, R.S., A.P.; supervision, R.S., A.F., A.S. (Alexey Shapagin), B.E. All authors have read and agreed to the published version of the manuscript.

Funding: The study was supported by the Ministry of Science and Higher Education of the Russian Federation (project number AAAA-A16-116121410087-6). The authors acknowledge the Center of the collective use of physical methods of investigation of A.N. Frumkin Institute of Physical Chemistry and Electrochemistry of the Russian Academy of Sciences.

Data Availability Statement: Not applicable.

Conflicts of Interest: Competing interests (include appropriate disclosures). There was no conflict of interest.

\section{References}

1. Bykov, G.L.; Ershov, B.G. Sorption of uranyl ions on phosphorylated lignin. Radiochemistry 2009, 51, 292-294. [CrossRef]

2. Suflet, D.M.; Chitanu, G.C.; Popa, V.I. Phosphorylation of polysaccharides: New results on synthesis and characterisation of phosphorylated cellulose. React. Funct. Polym. 2006, 66, 1240-1249. [CrossRef]

3. Lehtonen, J.; Hassinen, J.; Kumar, A.A.; Johansson, L.-S.; Mäenpää, R.; Pahimanolis, N.; Pradeep, T.; Ikkala, O.; Rojas, O.J. Phosphorylated cellulose nanofibers exhibit exceptional capacity for uranium capture. Cellulose 2020, 27, 10719-10732. [CrossRef]

4. Klemm, D.; Philipp, B.; Heinze, T.; Heinze, U.; Wagenknecht, W. Comprehensive Cellulose Chemistry Volume 1; Wiley: Hoboken, NJ, USA, 2012; ISBN 9781118241455.

5. Luneva, N.K.; Ezovitova, T.I. Cellulose phosphorylation with a mixture of orthophosphoric acid and ammonium polyphosphate in urea medium. Russ. J. Appl. Chem. 2014, 87, 1558-1565. [CrossRef]

6. Ferrer, A.; Pal, L.; Hubbe, M. Nanocellulose in packaging: Advances in barrier layer technologies. Ind. Crops Prod. 2017, 95, 574-582. [CrossRef]

7. Kettunen, M.; Silvennoinen, R.J.; Houbenov, N.; Nykänen, A.; Ruokolainen, J.; Sainio, J.; Pore, V.; Kemell, M.; Ankerfors, M.; Lindström, T.; et al. Photoswitchable superabsorbency based on nanocellulose aerogels. Adv. Funct. Mater. 2011, $21,510-517$. [CrossRef]

8. Mat Zain, N.F. Preparation and Characterization of Cellulose and Nanocellulose From Pomelo (Citrus grandis) Albedo. J. Nutr. Food Sci. 2014, 5, 334. [CrossRef]

9. Mautner, A.; Lee, K.Y.; Tammelin, T.; Mathew, A.P.; Nedoma, A.J.; Li, K.; Bismarck, A. Cellulose nanopapers as tight aqueous ultra-filtration membranes. React. Funct. Polym. 2015, 86, 209-214. [CrossRef]

10. Nair, S.S.; Zhu, J.; Deng, Y.; Ragauskas, A.J. High performance green barriers based on nanocellulose. Sustain. Chem. Process. 2014, 2,1-7. [CrossRef]

11. Voisin, H.; Bergström, L.; Liu, P.; Mathew, A. Nanocellulose-Based Materials for Water Purification. Nanomaterials $2017,7,57$. [CrossRef]

12. Werber, J.R.; Osuji, C.O.; Elimelech, M. Materials for next-generation desalination and water purification membranes. Nat. Rev. Mater. 2016, 1, 1-15. [CrossRef]

13. Klemm, D.; Kramer, F.; Moritz, S.; Lindström, T.; Ankerfors, M.; Gray, D.; Dorris, A. Nanocelluloses: A new family of nature-based materials. Angew. Chemie-Int. Ed. 2011, 50, 5438-5466. [CrossRef]

14. Ghanadpour, M.; Carosio, F.; Larsson, P.T.; Wågberg, L. Phosphorylated Cellulose Nanofibrils: A Renewable Nanomaterial for the Preparation of Intrinsically Flame-Retardant Materials. Biomacromolecules 2015, 16, 3399-3410. [CrossRef]

15. Granja, P.L.; Pouységu, L.; Pétraud, M.; De Jéso, B.; Baquey, C.; Barbosa, M.A. Cellulose phosphates as biomaterials. I. Synthesis and characterization of highly phosphorylated cellulose gels. J. Appl. Polym. Sci. 2001, 82, 3341-3353. [CrossRef]

16. Gospodinova, N.; Grelard, A.; Jeannin, M.; Chitanu, G.C.; Carpov, A.; Thiéry, V.; Besson, T. Efficient solvent-free microwave phosphorylation of microcrystalline cellulose. Green Chem. 2002, 4, 220-222. [CrossRef]

17. Sander, M.; Steininger, E. Chapter 5: Phosphorylation of Polymers. J. Macromol. Sci. Part C 1968, 2, 57-72. [CrossRef]

18. Sud, D.; Mahajan, G.; Kaur, M.P. Agricultural waste material as potential adsorbent for sequestering heavy metal ions from aqueous solutions-A review. Bioresour. Technol. 2008, 99, 6017-6027. [CrossRef] [PubMed]

19. Ojedokun, A.T.; Bello, O.S. Sequestering heavy metals from wastewater using cow dung. Water Resour. Ind. 2016, 13, 7-13. [CrossRef]

20. Yuan, H.-B.; Tang, R.-C.; Yu, C.-B. Flame Retardant Functionalization of Microcrystalline Cellulose by Phosphorylation Reaction with Phytic Acid. Int. J. Mol. Sci. 2021, 22, 9631. [CrossRef]

21. Ait Benhamou, A.; Kassab, Z.; Nadifiyine, M.; Salim, M.H.; Sehaqui, H.; Moubarik, A.; El Achaby, M. Extraction, characterization and chemical functionalization of phosphorylated cellulose derivatives from Giant Reed Plant. Cellulose 2021, 28, 4625-4642. [CrossRef]

22. Harada, N.; Mitsukami, Y.; Uyama, H. Energy-Efficient Preparation Method of Water-Swellable Starch Phosphate Carbamate Particles. Starch-Stärke 2021, 73, 2000119. [CrossRef] 
23. Kassab, Z.; Kassem, I.; Hannache, H.; Bouhfid, R.; Qaiss, A.E.K.; El Achaby, M. Tomato plant residue as new renewable source for cellulose production: Extraction of cellulose nanocrystals with different surface functionalities. Cellulose 2020, 27, 4287-4303. [CrossRef]

24. Hokkanen, S.; Repo, E.; Suopajärvi, T.; Liimatainen, H.; Niinimaa, J.; Sillanpää, M. Adsorption of Ni(II), Cu(II) and Cd(II) from aqueous solutions by amino modified nanostructured microfibrillated cellulose. Cellulose 2014, 21, 1471-1487. [CrossRef]

25. Guo, X.; Feng, Y.; Ma, L.; Yu, J.; Jing, J.; Gao, D.; Khan, A.S.; Gong, H.; Zhang, Y. Uranyl ion adsorption studies on synthesized phosphoryl functionalised MWCNTs: A mechanistic approach. J. Radioanal. Nucl. Chem. 2018, 316, 397-409. [CrossRef]

26. Sirviö, J.A.; Hasa, T.; Leiviskä, T.; Liimatainen, H.; Hormi, O. Bisphosphonate nanocellulose in the removal of vanadium(V) from water. Cellulose 2016, 23, 689-697. [CrossRef] 